\title{
AMBIENTE: ¿NUEVA CUESTIÓN SOCIAL PARA EL TRABAJO SOCIAL?
}

\section{THE ENVIRONMENT: AN EMERGING SOCIAL ISSUE FOR SOCIAL WORK?}

\section{Hannia Franceschi Barraza*}

\author{
RESUMEN
}

Se propone la problemática ambiental como un campo de acción del Trabajo Social, bajo el supuesto de que es una manifestación de cuestiones sociales contemporáneas. La cuestión ambiental se genera cuando los recursos naturales se conciben como mercancía objeto de lucro, en detrimento del acceso público que demanda la ciudadanía. Se concluye con líneas de acción interdisciplinarias y especificidades disciplinarias, aportadas desde la dimensión socioeducativa de la profesión en América Latina.

PALABRAS CLAVE: COSTA RICA * TRABAJO SOCIAL * MEDIO AMBIENTE * MOVIMIENTOS SOCIALES * INTERDISCIPLINARIEDAD

\section{ABSTRACT}

The environmental crisis is proposed as a framework of action for Social Work, based on the assumption that it is a manifestation of contemporary social issues. The environmental crisis is a result of conceptualizing natural resources as commodities for profit, at the expense of public access claimed by citizens. It concludes with interdisciplinary and discipline-specific strategies, contributed by the profession's socio-educative dimension in Latin America. KEYWORDS: COSTA RICA * SOCIAL WORK * ENVIRONMENT * SOCIAL MOVEMENTS *
INTERDISCIPLINARITY

Escuela Trabajo Social de la Sede de Occidente y Maestría en Desarrollo Sostenible, ambos de la Universidad de Costa Rica (UCR).

hanniaf@gmail.com 


\section{INTRODUCCIÓN ${ }^{1}$}

Un supuesto presente en los ámbitos académicos del Trabajo Social latinoamericano es la cuestión social, como referencia teórica para la generación de los objetos de conocimiento y actuación profesional. Es una categoría que ha sido trabajada ampliamente en los congresos y seminarios latinoamericanos de Trabajo Social, con énfasis en el tercer milenio $y$ ha tenido amplia repercusión en los ámbitos de la docencia y la investigación ${ }^{2}$.

La cuestión social como categoría de análisis, es parte constitutiva de las ciencias sociales críticas y tiene fundamento en la teoría marxista. Generalmente, se asume que esta connota tanto una dimensión estructural, referente a las desigualdades derivadas de la posesión de los medios de producción por parte de clases sociales antagónicas, como una dimensión coyuntural, relacionada con los procesos socio histórico concretos en los que se observan distintas manifestaciones, en términos de problemas sociales.

No obstante, la aplicación de la categoría cuestión social es polisémica, cuando se analizan realidades particulares, correspondientes a distintos contextos. Partiendo que en el mundo académico se dialoga entre paradigmas críticos (por ejemplo, marxismo clásico, neomarxismos), se encuentran diversas concepciones sobre la cuestión social, aunque todas puedan ser consideradas teorías críticas.

Entre las discrepancias o diferentes perspectivas sobre la cuestión social puede mencionarse la discusión sobre la preeminencia de la dimensión estructural (surgida en el siglo xIx y

$1 \quad$ Este artículo surge de la reflexión sobre el tema ambiental y social, como parte del trabajo docente de la autora en niveles de grado y posgrado en la Universidad de Costa Rica. Una versión preliminar de este artículo se presentó como ponencia al v Congreso Internacional $y$ viII Nacional de Trabajo Social, realizado en setiembre de 2010 , en San José, Costa Rica.

2 Se mencionan autores $y$ autoras participantes de esa discusión, entre ellos a: José Paulo Netto, Marilda Iamamoto y Potyara Pereira, de nacionalidad brasileira; a Margarita Rozas y a Silvia Fernández, de nacionalidad argentina y a Lorena Molina, de Costa Rica. con manifestaciones actuales) o si más bien, se está ante nuevas cuestiones sociales en el mundo contemporáneo, que manifiestan lo estructural y lo coyuntural en cada problemática concreta.

La primera posición la sustentan autores tales como Netto (2003), quien afirma que la cuestión social expresa las manifestaciones de las contradicciones sociales estructurales del capitalismo en las distintas sociedades y tiempos históricos. Al analizar el predominio del neoliberalismo y globalización en las últimas décadas, considera que prevalecen las contradicciones fundamentales del sistema capitalista, constituyendo la razón de ser del Trabajo Social, por lo cual deduce que se cuenta con referentes sustantivos profesionales para el presente y futuro (2003: 68).

La segunda posición la sostiene Rosanvallón (1995), al analizar los cambios sucedidos en las sociedades occidentales desde comienzos de los años 90, con el advenimiento de la crisis del Estado de Bienestar. Este autor parte de la premisa que actualmente estamos ante una nueva cuestión social, derivada de una crisis, que más allá de los problemas financieros y de gestión, implica una revisión profunda de los principios organizadores del Estado contemporáneo en la atención de lo social, los cuales se basaban en los principios de la solidaridad y en los derechos sociales (1995: 8-12).

En la misma línea de la nueva cuestión social, Castel afirma que "el nuevo régimen del capitalismo contemporáneo... destruye sin piedad los sistemas de regulación y protección que se habían construido alrededor del trabajo" (2005: 25). En ese mismo escenario, "vastos sectores de la sociedad ya no saben muy bien quiénes son, a qué conjunto o clase pertenecen, qué es lo que los relaciona a unos con otros. En definitiva, no saben adónde los lleva la situación actual, porque temen vivir mañana peor que hoy" (Pérez, 2005: 20).

Sin duda, Castel y Pérez refieren a la crisis de identidades colectivas en la nueva cuestión social, derivada de la desregulación y de los profundos cambios en la organización del mundo del trabajo. Al respecto, conviene tener en cuenta que actualmente, las viejas formas de movilización social de los sindicatos 
de trabajadores urbanos y rurales, no son las principales estrategias de lucha para enfrentar las crecientes desigualdades y opresiones de las clases subalternas, porque se han desestructurado las tradicionales formas de contratación laboral en las ciudades y en el campo.

En una posición distinta a la de los últimos dos autores mencionados, pero también alejándose del determinismo estructural de la cuestión social que plantea Netto, Pereira $(2003)^{3}$ concibe que la cuestión social trasciende la contradicción capital-trabajo o entre fuerzas productivas y relaciones de producción. Agrega que una cuestión social existe cuando emerge un conflicto social entre actores con intereses de clase contradictorios, de manera tal que los que están en condiciones de dominación, problematizan el orden establecido mediante acciones colectivas; se desprende así que la política es un elemento central para la constitución de la cuestión social. Si esas condiciones aún no están dadas, no se podría hablar de una cuestión social propiamente constituida, sino de una cuestión social latente "cuya explicitación acaba por transformarse en el principal desafío de las fuerzas sociales progresistas" (Pereira, 2003: 73).

Los autores brasileños Netto y Pereira coinciden en la centralidad de la dimensión económico estructural de la cuestión social; no obstante, discrepan en el peso de lo socio político. Según Pereira, son fundamentales los procesos de organización y movilización social, como condición para que un problema o necesidad social se convierta en cuestión social.

Continuando con la argumentación de la prioridad de lo político social en la comprensión de la cuestión social, Coraggio y Arancibia hacen un interesante aporte al debate, cuando afirman:

... entenderemos como cuestión social en una sociedad capitalista con formas democráticas al entramado de problemas interdependientes, con significado social,

$3 \quad$ Pereira explica que una cuestión es un problema por resolver, un punto de partida del conocimiento, que implica resolución cognitiva y práctica (2003: 83). jerarquizados $y$ articulados, que amenazan la cohesión de la sociedad como tal. Ese entramado desafía imperiosamente a los actores políticos - para su sostenimiento legítimo como tales- a actuar, producir discursos y tomar posiciones respecto a la jerarquización de tales en un todo, así como a las vías y a las responsabilidades para su gestión pública y resolución (2004: 1-2).

Se encuentra un elemento nuevo en el razonamiento de Coraggio y Arancibia, al vincular cuestión social con la gestión pública, en otras palabras, a las políticas estatales que deben darle resolución a las demandas de los actores sociales organizados.

Ese autor refiere también a la nueva cuestión social, al considerar que:

Así, en la actualidad, el dramático aumento en la cantidad de pobres, de desocupados, de trabajadores pobres precarizados o no plenamente ocupados, y del grado de concentración de la riqueza, particularmente del capital financiero, $y$ su persistencia pasada $y$ previsible, significan un cambio en calidad de la o las posibles cuestiones sociales. En esta situación, el campo teórico práctico (y sus "especialistas") es demandado y tensionado desde la ineludible búsqueda de respuestas políticas, porque la reproducción de tal situación socava la hegemonía del bloque en el poder, que no puede por mucho tiempo limitarse a administrar la crisis de reproducción social, y por tanto se abre una brecha para la lucha cultural contrahegemónica desde el campo popular (2004: 2).

Al relacionar cuestión social y poder político gestado desde la sociedad, ante las contradicciones generadas en la economía y la reproducción social del capitalismo contemporáneo, los autores que plantean una nueva cuestión social reconocen la importancia de las acciones colectivas de las clases subalternas.

Esa perspectiva analítica es básica para comprender que las actuales formas 
de exclusión y empobrecimiento pueden dar origen a manifestaciones sociales y a políticas que cuestionan la apropiación de capital en sus expresiones presentes. Son otras formas de luchas de clase, que no se circunscriben a la defensa del salario y de los ingresos de los productores independientes, sino que ahora problematizan la distribución de riquezas colectivas de dominio público como por ejemplo, las naturales.

\section{CUESTIÓN SOCIAL Y AMBIENTE}

Desde la perspectiva de análisis que se viene sustentado, surge la interrogante de que si el tema ambiental podría manifestar una cuestión social contemporánea. Es importante relacionar las dimensiones estructurales y coyunturales del capitalismo actual, así como, sus manifestaciones en el campo ambiental, partiendo de que las desigualdades antagónicas entre las clases sociales, las confronta en la pugna por el acceso y manejo de los recursos naturales. Se afirma que el modelo de desarrollo extractivo y depredador, considera a la naturaleza como otra mercancía para capitalizar, tal y como lo concibe Gudynas:

La mercantilización (commodification) de la naturaleza avanza al fragmentarla en los llamados "bienes y servicios ambientales" $y$ en distintas mercaderías para insertarla en los procesos productivos. Los componentes de los ecosistemas, sean especies de fauna o flora 0 , incluso, sus genes o sus ciclos ecológicos, se convierten en mercancías sujetas a las reglas del comercio, que pueden tener dueños y valor económico (2010: 62).

Sin embargo, hasta hace poco tiempo, se entendía que el ambiente estaba al margen de la lógica de producción y del consumo, y que las políticas públicas estaban separadas de la economía. En este contexto, surge un nuevo pensamiento acerca de lo ambiental en América Latina, con planteamientos de autores como Leff:

Implica repensar toda la historia del mundo a partir de la escisión entre el ser como ente, del "error platónico" que dio falsos fundamentos a la civilización occidental: que engendró la ciencia moderna como dominación de la naturaleza; que produjo la economización del mundo e implantó la ley globalizadora y totalizadora del mercado (2003: 9).

Este autor cuestiona las teorías y cosmovisiones que han influido en los enfoques científicos de la modernidad y por ende, en los modelos de desarrollo económico, social y cultural vigentes, que incluyen el ambiente. Por eso es importante referirse a dos perspectivas que han estado presentes en las concepciones sobre lo ambiental en tiempos actuales:

1) Como lo salvaje, lo primitivo, la barbarie, que debe ser domada por lo civilizado, lo moderno, lo científico. Aquí se concibe un uso depredador, extractivo de los recursos naturales en la producción económica, evidente en la industria forestal, en la pesca industrial, en la minera metálica, entre otros ejemplos. Esas prácticas extractivas ocultan sus impactos profundos en los ecosistemas frágiles, ante los cuales, las acciones estatales $y$ privadas han planteado generalmente medidas de mitigación.

2) Como la reserva de lo bello y lo bueno, el espacio de la salud, de la vida integral: cuando se relaciona esta visión del paisaje natural con negocios lucrativos (sobre todo de gran magnitud), se podría incurrir en posiciones utilitaristas, de provecho económico para aquellos dueños de grandes capitales que invierten en negocios relacionados con el ambiente natural (Moura, 2003: 95-99).

Una $y$ otra perspectiva pueden llevar a posiciones antropocéntricas, en las que predominan los intereses humanos sobre la naturaleza. Además, hay un interés de lucro en ambas concepciones, que visualizan a la naturaleza como negocio, dando como resultado la captación de utilidades por parte de los sectores y actores con mayor poderío económico-político. 
Desde estos supuestos analíticos, se plantea que existen manifestaciones de la cuestión social ambiental en la actualidad, que se concretan en procesos políticos particulares como el de Costa Rica.

\section{PROCESO DE POLITIZACIÓN DEL TEMA AMBIENTAL EN COSTA RICA: SU VÍNCULO A LA CUESTIÓN SOCIAL}

Se pretende argumentar la construcción de la cuestión social ambiental, a partir de la trayectoria histórica de algunos procesos de organización y lucha social, en torno a la problemática ambiental de los últimos 40 años.

Desde los años 70 hasta la actualidad, se puede identificar una presencia sostenida del tema ambiental en las acciones colectivas de las organizaciones sociales comunitarias, protagonizadas en distintas escalas del territorio nacional ${ }^{4}$.

En el decenio de los 70, destaca la lucha contra un contrato de ley para entregar una parte del territorio sur de Costa Rica, en concesión por 99 años a la transnacional Aluminium Company of América (ALCA), autorizándole la extracción de aluminio.

En la misma década, emerge una lucha contra dos grandes proyectos de infraestructura: una carretera a través del Parque Nacional Braulio Carrillo, de gran riqueza natural, así como, la construcción de un oleoducto interoceánico. Ambos proyectos correspondían al auge del modelo agroexportador desarrollista, que requería de facilidades en el transporte vehicular y del combustible, desde la costa del Océano Pacífico hacia la Costa Atlántica (Mar Caribe).

Desde entonces, empieza a decantarse una disputa en cuanto al uso y acceso de los recursos naturales, por un lado, entre las grandes empresas $y$ sus aliados en el gobierno $y$ por

$4 \quad$ La delimitación del análisis de la problemática ambiental de las últimas cuatro décadas (desde los años 70 al presente) guarda relación con una presencia sostenida del tema, por parte de diversos actores sociales y en distintas provincias del territorio nacional. No niega la existencia de conflictos ambientales en otras épocas históricas y por otro lado, ocurre también que no están documentadas. otro, las comunidades preocupadas por sus condiciones de vida.

Sin embargo, conviene destacar que tales luchas no surgen aisladas, por el contrario, cuentan con condicionantes externos que propiciaban una emergente conciencia ambientalista:

Ese despegue del movimiento ambientalista en Costa Rica en los años setenta debe relacionarse con un contexto internacional donde ocurrieron hechos significativos, como lo fue la emisión del libro de Meadows Los límites del crecimiento, en 1972, el cual llamó la atención sobre los peligros que acarrearía el industrialismo y un crecimiento desmedido de la población, en la mantención de los recursos naturales del mundo. A la vez en el mismo año se realizó la Conferencia de las Naciones Unidas sobre Medio Ambiente $y$ entre sus acuerdos estuvo la creación del Programa de Naciones Unidas para el Medio Ambiente ( (рNuma). Asimismo tuvieron eco las ideas del movimiento hippie y los movimientos contraculturales de mayo 1968 en Francia, México (Tlatelolco) en el mismo año y en varias universidades estadounidenses (Berkeley, entre ellas) (Franceschi, 2002: 107).

En los años 80, se inician las luchas contra proyectos hidroeléctricos como la represa en el río Pacuare, la lucha por la defensa de una zona protectora de bosque primario (Reserva Juan Castro Blanco) y la defensa del atún en el Pacífico Oriental. También hay luchas contra los efectos de la contaminación ambiental generada por las fábricas, como la Metalco en la ciudad capital, como lo analiza Fallas (1993).

En la década de los 90, se identifican múltiples y variadas manifestaciones de luchas ambientales, que se pueden resumir en los siguientes ejes:

$\diamond \quad$ Deterioro y agotamiento de la naturaleza (recursos naturales) por sobrexplotación o contaminación del bosque, suelo y agua.

$\diamond \quad$ Insalubridad del entorno físico, generado por el manejo de los desechos humanos e industriales. 
$\diamond \quad$ Destrucción de bellezas escénicas (en las playas), como resultado de desequilibrios generados por la infraestructura turística (Mora, 1998: 126-127).

La tendencia descrita se acrecienta en el año 2000, en la protesta cívica contra el combo $\mathrm{ICE}^{5}$. Uno de los actores sociales presentes en la lucha son los sectores ecologistas, que se integran a la movilización popular organizada en oposición a la entrega de una institución pública, encargada de la generación de energía y de las telecomunicaciones a empresas privadas nacionales y extranjeras. Consideraban que el Instituto Costarricense de Electricidad (ICE) era una parte del patrimonio nacional (Alvarenga, 2005: 283). Un argumento que sostenía la lucha del sector ecologista (parte del movimiento ambientalista) era que el Ice garantizaba el uso de los recursos hídricos y energéticos como bien público.

El componente ambiental en diversas luchas sociales adquiere nueva preponderancia a partir del año 2000. Según el Programa Estado de la Nación es un tema que moviliza a la ciudadanía:

La gestión de los recursos naturales y en los que la tensión es entre la actividad productiva y la protección del ambiente llamaron la atención de la opinión pública, al punto de darle dimensión nacional a asuntos en apariencia locales. Se trata, entre otros, de los casos de la minería a cielo abierto en Crucitas de San Carlos, el uso del agua en las comunidades de Sardinal, en Guanacaste y Barva de Heredia (2009: 246).

Los temas relacionados con el agua, ya sea para consumo humano directo o como

$5 \quad$ "Combo IcE" recoge una expresión popular referida a un conjunto de leyes que en forma agrupada, pretendía aprobar el gobierno de turno, para iniciar un proceso de privatización del Instituto Costarricense de Electricidad (ICE). Este es una institución pública, que tuvo gran legitimidad entre la ciudadanía, hasta que las orientaciones neoliberales conservadoras empezaron a socavar su funcionamiento eficiente, en la prestación de servicios de electricidad y telefonía residencial y móvil. generador de energía hidroeléctrica, pasan a ser de interés político de la ciudadanía y de los movimientos sociales. Lo anterior, al evidenciarse que fuertes intereses económicos de grandes empresarios nacionales y extranjeros, pretendían un acceso privilegiado al recurso hídrico, en detrimento del acceso público y en consecuencia, en los derechos ciudadanos de las mayorías.

Frente a esa posición, los movimientos $y$ organizaciones sociales contestatarias argumentaban que el Estado debía permanecer como garante de la regulación equitativa del recurso hídrico. En otras palabras, los movimientos sociales valoraban que el agua debía ser defendida como un recurso público, con precios accesibles para toda la población, incluso, para la de bajos ingresos económicos. Un estudio elaborado por el Programa Estado de la Nación constata este análisis:

Las tensiones más serias se dieron en las regiones de Guanacaste, Osa y la zona norte, donde prevalecen bajos indicadores sociales... y paralelamente, se experimentan acelerados cambios en la dinámica económica (proyectos inmobiliarios y turísticos, minería) (2009: 251).

Resulta claro que el desarrollo económico en regiones alejadas del Valle Central de Costa Rica, expresa la tendencia hacia una apropiación privada de riquezas naturales. Estas se conciben como un negocio, con el interés de lucro por encima de la conservación del ambiente y de la generación de empleos de calidad, así como, del mejoramiento de las condiciones de vida de las poblaciones locales.

En la actualidad, los conflictos mencionados por el Programa Estado de la Nación no se han resuelto ${ }^{6}$. Quizás por esa razón, distintos actores sociales y políticos autónomos han

$6 \quad$ El Programa Estado de la Nación es un organismo estatal independiente del gobierno, dedicado a la investigación en temas económicos, sociales, políticos y ambientales, que cuenta con un financiamiento procedente de las universidades públicas agrupadas en el Consejo Nacional de Rectores (CONARE), de la Defensoría de los Habitantes y de otras entidades públicas. 
ampliado el cuestionamiento al manejo de la política económico-ambiental. Toman conciencia de que la defensa del ambiente en el discurso de los grandes inversionistas y del gobierno central, no garantiza el acceso generalizado a los recursos naturales para toda la ciudadanía.

Se han generado contradicciones entre esos actores con intereses diversos, incluso, al interior del Estado costarricense. Es así como las universidades públicas y en particular la Universidad de Costa Rica, aplicando su autonomía relativa de pensamiento, han jugado un papel fundamental en la denuncia de los impactos negativos de los tres proyectos mencionados: minería a cielo abierto en Crucitas (zona norte), acueductos privados con apoyo gubernamental en Guanacaste (Pacífico Norte) $y$ el desarrollo inmobiliario destinado a turismo residencial en el Pacífico Central. Esta institución manifiesta públicamente un análisis crítico al modelo de desarrollo extractivo, considerando que puede provocar deterioros significativos en la naturaleza y en la calidad de vida de las comunidades de las regiones. Este razonamiento se evidencia en el extracto del siguiente documento del Consejo Universitario de la Universidad de Costa Rica:

El caso del conflicto por el proyecto del acueducto en Sardinal, junto con otros en la región costera del Pacífico costarricense, evidencia que este modelo de desarrollo está conduciendo a situaciones límite, donde la disputa social entre actores transnacionales del negocio turístico e inmobiliario y las poblaciones locales, se han configurado en una lucha por el acceso y control de recursos vitales como el agua. Lo que al parecer implica el inevitable enfrentamiento social (Universidad de Costa Rica, 2009: 132).

Se observa en el pronunciamiento, una toma de posición de una universidad pública ante la sociedad y Estado costarricense, que pretende incidir en la opinión pública y en la gestión de políticas públicas ambientalistas.

La trayectoria de la problemática ambiental de los últimos 40 años en Costa Rica, expresa un proceso de politización de la cuestión ambiental, que en alguna medida, podría colocarla como cuestión social de interés para el Trabajo Social. Se han ido evidenciando conflictos por el acceso público o privado a los recursos naturales fundamentales para la reproducción social de la vida humana y natural, como el agua, el bosque y el suelo.

La resolución política del conflicto implica una toma de posición en dos direcciones: a favor de derechos ciudadanos, para satisfacer las necesidades humanas y mejorar las condiciones de vida de la mayoría del pueblo costarricense; en otro sentido, la búsqueda del uso lucrativo de los bienes públicos, respondiendo a los intereses de las compañías transnacionales, que en nombre del "progreso económico", impulsan mega proyectos, ocultando su impacto en el deterioro de los recursos naturales.

Surge aquí otra pregunta: ¿hasta qué punto está claro para el Trabajo Social el trasfondo económico-político de la problemática ambiental en tiempos del capitalismo contemporáneo?

\section{HACIA EL TRABAJO SOCIAL AMBIENTAL COMO CAMPO DE ACCIÓN PROFESIONAL}

Las y los profesionales en Trabajo Social incursionaron desde los años 90, en campos de acción interdisciplinarios, como el manejo comunitario de los desechos sólidos, la gestión local del riesgo (llamado anteriormente, desastres naturales) y la protección de recursos naturales como el agua y el bosque; proceso que ha permitido explorar las relaciones entre el tema ambiental y el trabajo profesional.

Para avanzar en la comprensión del ambiente como mercancía, se requiere develar si es una manifestación de las cuestiones sociales contemporáneas, evidenciándose en la problematización y movilización ciudadana ante las desigualdades en el acceso a bienes comunes como el agua y la generación de problemas de insalubridad pública, derivados de la industrialización y crecimiento urbano.

Se plantea a modo de hipótesis, que se encuentra ante una politización de la cuestión social ambiental, lo cual genera la apertura de un campo de acción en el Trabajo Social. Se entiende por campo aquel que "... se nutre de 
las manifestaciones de la cuestión social expresadas por los sujetos como demandas que constituyen el punto de partida de la intervención" (Rozas, 2004: 164).

Para contribuir a la conformación del campo del Trabajo Social ambiental, en el ámbito intelectual y profesional, se requiere colocar tal discusión en el contexto actual de la globalización económica neoliberal y esclarecer sus expresiones particulares en cada sociedad concreta. Implica análisis de coyuntura, que permita entender los determinantes y condicionantes de los problemas ambientales. Se proponen algunos de sus contenidos estratégicos como puntos de partida:

A) Áreas de acción específicas ${ }^{7}$ : dilemas para el trabajo profesional

$\diamond \quad$ Problemas y necesidades sociales de la pequeña producción de bienes y servicios: en sectores tales como, el agrícola, agroforestal, servicios de turismo rural comunitario, producción y comercialización de alimentos artesanales y artesanías textiles, en los que las personas dedicadas a la pequeña producción se enfrentan a contradicciones entre la conservación y preservación de recursos naturales y la satisfacción de sus necesidades básicas. Este dilema abre una veta de estudio y de práctica profesional, hacia la búsqueda de posibles escenarios de conciliación en ambas dimensiones.

$\diamond \quad$ Conflictos socio ambientales: se refiere a proyectos económico-sociales en pequeña escala, en los que surge una contradicción entre el aprovechamiento de recursos naturales (suelo, bosque y agua) con fines utilitaristas en el corto plazo y la conservación de recursos, con miras de mediano y largo plazo. El dilema surge

$7 \quad$ La propuesta de cuatro áreas de acción no es definitiva. Responde a la experiencia de investigación de la autora, en zonas rurales de Honduras y de Costa Rica; complementada con posteriores experiencias docentes en Costa Rica, en la dirección de trabajos finales de graduación. porque aprovechar los recursos naturales sin límite, implica actuar según intereses inmediatos, particulares. Cuando la acción se orienta a la conservación y preservación de recursos naturales, esta se basa en un enfoque global, de mediano $y$ largo plazo, en el que seres humanos $y$ naturaleza se conciben como parte del planeta Tierra y por tanto, deben buscar formas de convivencia, en respeto mutuo (Franceschi, 2006).

$\diamond \quad$ Impacto de amenazas naturales en la gestión local: se refiere a un tema comúnmente llamado desastres naturales, en los que las poblaciones humanas son consideradas víctimas de fuerzas sobrenaturales. Esa visión fisicalista se critica desde el enfoque de gestión local del riesgo, que analiza los desastres naturales como resultado de procesos sociales e históricos, en los que la acción del ser humano crea las condiciones que dan paso a su gestación. Este enfoque se concibe como una herramienta teórica metodológica, orientada a conocer los escenarios de riesgo desde las mismas personas que viven y provocan las consecuencias negativas. Incluye la construcción de estrategias de intervención para el abordaje de los desastres, a partir de los planteamientos propios de los actores sociales (Araya, Arias y Cerdas, 2002). De allí la importancia de acompañar los abordajes teórico metodológicos con procesos socioeducativos, para reflexionar sobre el rol que debe asumir la sociedad $y$ los diversos actores sociales, en la reducción del riesgo de desastres (Madriz y Rojas, 2009).

$\diamond \quad$ Manejo de desechos de los procesos productivos $y$ de servicios: los procesos de producción artesanal primaria de bienes y servicios generan desechos sólidos y líquidos, que si no se disponen adecuadamente, generan contaminación de aguas, suelo y aire. De esa manera, atentan contra la calidad de vida de seres humanos $y$ naturaleza, en zonas rurales y urbanas. Trabajar en esta área de acción implica 
revisar las percepciones socioculturales sobre los residuos, porque si se conciben como basura no importa su disposición. En contraste, si se conciben como desechos, preocupa su destino final $y$ por tanto, se requiere un tratamiento adecuado, que no impacte en forma desmedida los procesos sociales y naturales, relacionados con las condiciones de vida de poblaciones humanas (Rojas, 2009).

Las áreas de acción propuestas como campos de actuación profesional, implican dilemas para el trabajo profesional, cuya resolución dependerá de las concepciones ético políticas y teóricas que asuman los sujetos en la comprensión de la problemática ambiental y su relación con las políticas públicas.

B) La problemática ambiental como parte de las políticas públicas de atención a la cuestión social

A propósito de la relación entre problemática social y cuestión social:

... los llamados "problemas sociales" surgen cuando la cuestión social se instala en la esfera pública y es legitimada por la acción social del Estado. Ello es problematizado en tanto el Estado, como instancia de fuerzas sociales, al mismo tiempo, desarrolla acciones de carácter coercitivo y de consenso. Este juego contradictorio es la dinámica que adquiere la atención de la cuestión social en distintos momentos históricos (Rozas, 2004: 157).

La problemática ambiental podría tener relación con las políticas sociales y desde allí, con una cuestión social de interés para el Trabajo Social, colocando la "ciudadanía" como categoría de enlace para el análisis.

Las tensiones entre apropiación privada $y$ dominio público de recursos naturales como agua, bosque y suelo, expresan una conflictividad relacionada con el acceso a derechos ciudadanos (sin distingos de clase, étnia, género $y$ etarias) para los diversos sectores sociales $y$ geográficos de nuestras comunidades. Mediante acciones colectivas de la ciudadanía, reivindicando esos derechos ambientales, se pueden provocar respuestas en la institucionalidad de las políticas públicas. Fernández (2005) nos aclara esta idea, cuando afirma que:

El trabajo en la ampliación y garantía de la ciudadanía implica una concepción de la política basada en la participación y el protagonismo colectivos en la definición y resolución de los problemas de la comunidad (local, regional, nacional). En este sentido debemos, como actor político, luchar en pos de los procesos de democratización político social (2005: 161).

Este es un desafío para las y los trabajadores sociales, que implica incorporar el ambiente como otro campo de su quehacer profesional en las políticas públicas.

C) De lo multi hacia lo inter $y$ transdisciplinario

Evidentemente el tema ambiental no es un campo propio de una disciplina, tampoco de las ciencias naturales, como se afirma comúnmente. Se está ante un campo transdisciplinario, cuya comprensión en referencia al Trabajo Social es argumentada por Escalada, en estos términos:

Por eso, de hecho, desde la particularidad de nuestra intervención profesional, necesitamos permanentemente pasarnos al otro lado, constituido por las más diversas disciplinas $y$ construir entre todos/as la síntesis que incluye los diferentes saberes. La gran pregunta es si el Trabajo Social y sus profesionales necesitamos una formación más profunda y más amplia que nos permita contar con más y mejores conocimientos para poder navegar con facilidad entre los distintos conocimientos, o internalizar la necesidad de trabajar con equipos, como única manera de resolver la mirada estrecha de una sola disciplina; o bien desarrollar ambas posibilidades (2005: 186). 
Esta autora llama a diversificar la formación profesional, para abordar desde enfoques más globales, complejos y multidimensionales, los objetos de conocimiento y acción, frente a una realidad social que se ha fragmentado en la división socio técnica de las profesiones.

Se hace necesario incursionar en investigaciones profundas y densas teóricamente, que cuestionen los problemas socio ambientales dentro de la dinámica de las sociedades capitalistas contemporáneas y sus expresiones particulares en cada país y región.

\section{D) El lugar de lo disciplinario}

Considerando que el campo de acción ambiental es de abordaje multi, inter $y$ transdisciplinario, no implica que se desdibujen los aportes disciplinarios, en este caso, del Trabajo Social.

Las contribuciones específicas del Trabajo Social que se proponen, a partir del acervo teórico metodológico socioeducativo, cultivado a lo largo de la trayectoria como profesión y de la práctica docente-investigativa, se sintetiza en la concepción teórico práctica de participación social y comunitaria, de la gestión participativa de proyectos, de la investigación acción participativa $y$ de la sistematización de experiencias con participación activa de los sujetos involucrados. En ese terreno hay bastante camino avanzado en Costa Rica y en muchos países de América Latina, por lo cual no se estaría empezando algo totalmente nuevo, sino articulando el campo de actuación con nuevas perspectivas $y$ asumiendo el desafío de producir conocimiento científico en diálogo interdisciplinario.

\section{E) La dimensión técnico-operativa}

$\mathrm{Su}$ abordaje requiere distinguir niveles de acción, que podrían precisarse de la siguiente manera:

$\diamond \quad$ A nivel local: administración de proyectos y servicios sociales dirigidos a la población en condición de pobreza, que vive en asentamientos en riesgo biofísico y expuesta a amenazas derivadas de eventos naturales. Además, esos sectores empobrecidos pueden incurrir en prácticas de degradación ambiental, como la corta de árboles para leña $y$ viviendas en zonas de protección de ríos y manglares. Esas prácticas los hacen doblemente vulnerables a riesgos de subsistencia y a riesgos biofísicos.

$\diamond \quad$ A nivel regional: elaboración de diagnósticos y planificación en escala territorial regional, coordinados con municipios $y$ organismos no gubernamentales. Esas acciones profesionales deben fundamentar la toma de decisiones de política pública en el ámbito de la planificación urbana y el desarrollo rural, en las cuales se relacione la dimensión ambiental con la dimensión económica y sociocultural.

Las funciones profesionales que se pueden realizar en esta dimensión técnico operativa, están legitimadas en otros campos de la profesión, entre ellos la investigación social, planificación, administración, ejecución y evaluación de proyectos sociales. Empero, resultan de especial importancia, la investigación, la educación y la promoción socio ambiental, aplicadas en forma complementaria y fundamentadas en perspectivas críticas de la problemática socio ambiental.

\section{CONCLUSIÓN}

La problemática ambiental podría considerarse una cuestión social en Costa Rica, a partir de la evidencia de acciones colectivas de organizaciones y movimientos sociales, que reaccionan ante la omisión o permisividad de instituciones estatales que desprotegen los bienes comunes (agua, suelo, bosques y aire) patrimonio natural de toda la sociedad y más bien, facilitan la apropiación privada que pretenden las grandes empresas transnacionales. Actores que los han convertido en mercancías objetos de lucro, lo cual ha generado una paulatina toma de conciencia en la ciudadanía sobre las implicaciones de un modelo de desarrollo extractivo y depredador, en tiempos contemporáneos del capitalismo.

Interpretar lo ambiental en ese contexto explicativo, podría orientar el trabajo académico 
$y$ profesional, a partir de una perspectiva teórica y política cuestionadora de tendencias que naturalizan lo ambiental, considerando que es parte de las ciencias biofísicas y que guarda poca relación con las estrategias de desarrollo económico vigente.

Esta posición implica asumirla en forma inter o transdisciplinaria entre las ciencias sociales, económicas, naturales y sociales; así también en alianza con movimientos sociales que actuando en defensa de sus derechos de ciudadanía, visualizan los asuntos ambientales como parte de las luchas por políticas públicas inclusivas de las necesidades de las mayorías.

Actualmente, existe un sendero avanzado hacia este horizonte. Desde campos de acción legitimados para el Trabajo Social, podrían gestarse acciones profesionales que se relacionen con perspectivas ambientales. Se proponen algunas áreas de acción profesional emergentes dentro del Trabajo Social, como son los problemas y necesidades sociales de la pequeña producción de bienes y servicios, el manejo de desechos de los procesos productivos y de servicios, los conflictos socio ambientales y las amenazas naturales, en las cuales se ha venido incursionando en décadas recientes.

Desde esta lectura, se está contribuyendo desde el Trabajo Social a la construcción de una ciudadanía ambiental, en el marco de una ciudadanía social que articula múltiples derechos, en procura de la satisfacción de derechos económicos y sociales, altamente lesionados en la era de la globalización neoliberal.

\section{BIBLIOGRAFÍA}

LIBROS

Alvarenga, Patricia. De vecinos a ciudadanos. San José: Editorial de la Universidad de Costa Rica y Editorial de la Universidad Nacional, 2005.

Escalada, Mercedes. "Volver a definir el Trabajo Social para servir al desarrollo humano". El Trabajo Social y la cuestión social. Crisis, movimientos y ciudadanía. Silvia Fernández (coord.). Buenos Aires: Espacio Editorial, 2005.
Fallas, Óscar. Modelos de desarrollo y crisis ambiental en Costa Rica. San José: Asociación Ecologista Costarricense (AEC), 1993.

Fernández, Silvia. "Políticas sociales, ciudadanía y espacio público". El Trabajo Social y la cuestión social. Crisis, movimientos y ciudadanía. Silvia Fernández (coord.). Buenos Aires: Espacio Editorial, 2005.

Leff, Enrique. "Pensar la complejidad ambiental". La complejidad ambiental. Enrique Leff (coord.). México: Siglo xxı Editores, 2003.

Mora, Eduardo. Naturaleza, qué herida mía. Heredia: Ambientico Editores y Universidad Nacional, 1998.

Moura, Isabel. "Los sentidos de lo ambiental. La contribución de la hermenéutica a la pedagogía de la complejidad". La complejidad ambiental. Enrique Leff (coord.). México: Siglo Xxi Editores, 2003.

Netto, José Paulo. "Cinco notas a propósito de la cuestión social". Servicio Social Crítico. Sao Paulo: Editora Cortez, 2003.

Pereira, Potyara. "Cuestión social, servicio social y derechos de ciudadanía". Servicio Social Crítico. Sao Paulo: Editora Cortez, 2003.

Programa Estado de la Nación en Desarrollo Humano Sostenible. "Armonía con la naturaleza". Informe Estado la Nación en Desarrollo Humano Sostenible. San José: Programa Estado de la Nación, Consejo Nacional de Rectores (conare), Defensoría de los Habitantes e Instituto de Fomento Cooperativo (infocoop), 2009.

Rosanvallón, Pierre. La nueva cuestión social. Repensar el Estado Providencia. Buenos Aires: Ediciones Manantial, 1995.

Rozas, Margarita. "¿Cómo asumir el estudio de la cuestión social y las políticas sociales en la formación profesional. Trabajo Social?". La cuestión social y la formación profesional en Trabajo Social en el contexto de las nuevas relaciones de poder y la diversidad latinoamericana. María Lorena Molina (org.). Buenos Aires: Espacio Editorial, 2004. 
REVISTAS

Franceschi, Hannia. "Trayectoria socio política del movimiento ambientalista en Costa Rica". Ínter Sedes (3). Universidad de Costa Rica, 2002: 105-113.

Franceschi, Hannia. "Conflictos socio ambientales intercampesinos por los recursos naturales". Revista de Ciencias Sociales 111-112. Universidad de Costa Rica, 2006: 37-56.

TESIS

Araya, Magda; Arias, Cristina y Cerdas, Laura. "Si no unimos lo que tenemos nadie va a hacerlo... gestión local para la reducción del riesgo ante los desastres en Cachí, Paraíso, Cartago". [Tesis de Licenciatura en Trabajo Social]. Escuela de Trabajo Social, Universidad de Costa Rica, 2002.

Madriz, Yanori y Rojas, Glenda. "Contribuyamos a reducir el riesgo: gestión local para la prevención de desastres en los Barrios Bajo El Progreso, Lisimaco Chavarría y San José, Distrito Primero y San Isidro, cantón de San Ramón de Alajuela". [Memoria de proyecto de graduación de Licenciatura]. Sede de Occidente, Universidad de Costa Rica, 2009.

Rojas, Rosibel. "Participación social en la gestión para el manejo de los residuos sólidos en el cantón de Los Chiles de Alajuela". [Memoria de proyecto de graduación de Licenciatura]. Sede de Occidente, Universidad de Costa Rica, 2009.

\section{TEXTOS ELECTRÓNICOS}

Castel, Robert. "El proceso de individualización, fragilización de los soportes de identidad frente a la transformación del capital y del trabajo". Las manifestaciones actuales de la cuestión social. Guillermo Pérez Sosto (coord.). Buenos Aires: Instituto Di Tella, 2005. En: <http://www.unesco.org.uy/shs/ fileadmin/templates/shs/archivos/ manifestaciones.pdf.> [consultado el 5 de marzo de 2013].

Coraggio, José Luis y Arancibia, Inés. "Recuperando la economía: entre la cuestión social y la intervención social". Ponencia al Congreso Nacional de Trabajo Social: de Araxá a Mar del Plata, 35 años de Trabajo Social Latinoamericano. Mayo de 2004. En: <http://riless.org/components/ com_virtualtecas/assets/arquivos/46/ recuperando_la_economia_ultima_ versi_n_26_02_05.pdf.> [consultado el 9 de marzo de 2013].

Gudynas, Eduardo. "La ecología política de la crisis global y los límites del capitalismo benévolo". Iconos, Revista de Ciencias Sociales 36. Facultad Latinoamericana de Ciencias Sociales-Sede Académica de Ecuador, 2010: 53-67. En: <http://www. flacso.org.ec/docs/i3 6gudynas.pdf.> [consultado el 26 de mayo de 2013].

Pérez, Guillermo (coord.). "Introducción". Las manifestaciones actuales de la cuestión social. Buenos Aires: Instituto Di Tella, 2005. En: <http://www.unesco.org.uy/ shs/fileadmin/templates/shs/archivos/ manifestaciones.pdf.> [consultado el 5 de marzo de 2013].

Universidad de Costa Rica. Implicaciones del proyecto de ampliación del acueducto El Coco-Ocotal, Guanacaste, conocido como "Sardinal". 2009. En: <http://www.cu.ucr.ac.cr/documen/ informeFinalSardinal.pdf $>$ [consultado el 30 de junio de 2010].

Fecha de ingreso: 08/11/2012 Fecha de aprobación: 03/07/2013 